\title{
Analysis and Tests of TF Magnet Insulation Samples for the JET Upgrade to 4 Tesla
}

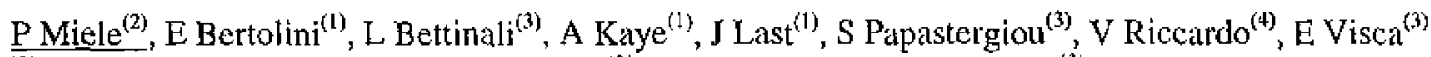 \\ ${ }^{(1)} J E T$ Joint Undertaking, Abingdon, UK, ${ }^{(2)}$ CERN, Geneva, Switzerland, ${ }^{(3)}$ ENEA, Frascati (Roma), \\ Italy; ${ }^{(4)}$ UKAEA Fusion, Culham, UK
}

\begin{abstract}
The JET Toroidal Field (TF) coils were originally designed for operation at $\mathbf{3 . 4}$ tesla. In order to upgrade the field to 4 tesla and thus improve the performance of the JET machine, now mechanical tests and analysis were carried out on the insulation of TF coil samples. They are aimed at investigating the mechanical properties and the status of the insulation in order to set allowable stresses and force limits. In particular since the shear stress in the insulation is strongly affected by the shear modulus of elasticity $G$, it is important to measure this parameter, A method for the mensurement of $G$ in glass-resin fibres, the $V$-notched beam method (losipeseu method), was applied. The particular shape of the rectangular Iosipescu $V$-notched anmple and the particular modality of foree application produce pure shear stress for a reliable measurement of the $G$ yalue and of the shear strength of the insulation. The effect of temperature on these mechanical properties was also investigated. Results show ligher average shear strength with lower scatter compared with previous tests on conventional rectangular samples, thus conlirming the reliability of the mothod. Micrographic analysis of the insulation and comparison between the straight and curved regions of the magnet, where the lighest stress occurs, conftrm the good quality of the impregnation of the coil. Glass-resin content, void content, nicros and TG measurements have been performed on different samples and currelation between the different properties of the insulation investigated. Moreover fatigue tests at different temperatures were performed and data analyzed with the cumulative damage technique, which allows for an extrapolation of the fatigue eurve with less snmples than the standard method.
\end{abstract}

\section{INTRODUCTION}

The JET toroidal field (TF) magnet system, Fig. 1, comprises $32 \mathrm{D}$-shaped coils originally designed to produce a field of $3.45 \mathrm{~T}$ at $2.96 \mathrm{~m}$ radius. Water-cooled and lately freon-cooled copper conductors and glass fïbres-epoxy resin insulation are the main components of the coils. In-plane and out-of-plane forces created by the electromagnetic ellect increase with the toroidal magnetic freld B. In order to assess the condition of the TF magnet system for the implementation of the upgrade of the JET machine to 4 T' operation, new analyses and tests have been made. The

Manuscript Jeccived Sept 26, 1999

P Misle, E-Mail: Pnola.Miele@ cem.ch obtained data give the basis for the reviow of allowable stress and force limits.

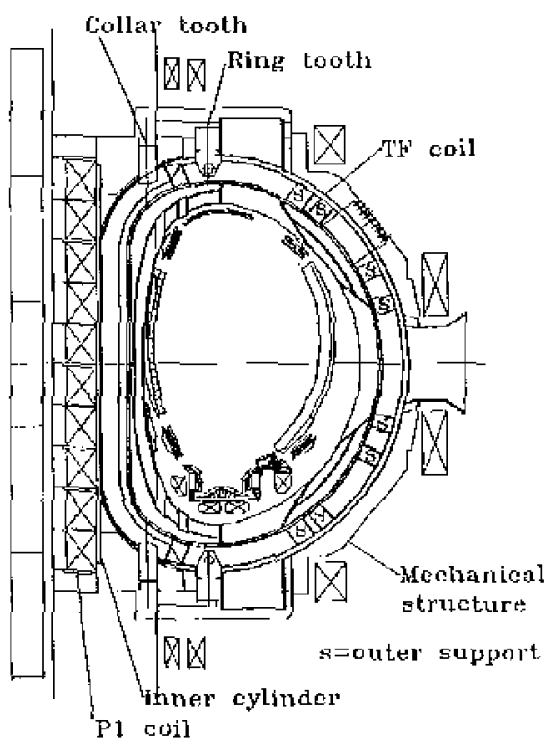

Fig. $1 . \Lambda$ cross section of the JET machine showing a TF coil with its supports.

\section{Mechanical ANalysis of tife, TH COILS}

The mechanical condition of the TF coils is assessed for any operational scenario of the JET machine. The $2 \mathrm{D}$ finite element plasma cquilitritun code MAXFEA (Maxwell Finite Element Analysis) calculates the poloidal fiedd (PF) and a 3D Biot Savart magnetic code the toroidal field, given the input parancters defining the particular scenario. The plasma parameters and $\mathrm{TI}^{2}$ and $\mathrm{PF}^{\mathrm{T}}$ coil etrrents are the input data for the calculation of the in-plate and oul-of-plane force distribution in the TF coils. Thereafter the stress distribution is computed by finite elements codes which are based on 2 models, the beam model [1] and the hybticl model [2]. The boam model gives the distribution along the coil of the mechanical stresses related to the particular operational scenario. The model consists of 136 beam elements, with smeared properties calculated across the section and support and load conditions as for the actual configuration. This represents a quick tool for the assessment of the averaged stresses in the section of the coil, accorcling to the classical beam theory. The hybrid model, Fig. 2, was created to investigale on the level of 
peak shear stress in the insulation itself in one of the most critjcal area of the coil, the third interturn at the collar tooth support arca. Figr. 3 shows a typical cross section of the TF coil, made up of 2 adjacent pancakes with 12 turns each. The insulation is divided in interturn, interpancake, key and ground insulation. The hybrid model consists of a 3D detailed model with brick elements of the area of interest and a beam model of the remaining coil. With the explicit modeling of the copper conductors and the glass-resin insulation in the section extra safety margin was found. Moreover key efficiency and delamination analysis was performed, which grives a trend of a crack non-propagation effect. Sensitivity analysis of the shear stress in the insulation with the shear modulus of elasticity $G$ was carricd out [2], which imposed the necessity to measure the actual value of the above montioned parameter. A new correlation between the reaction force at the collar tooth support and the related peak shear stress in the instlation was therefore set up for the measured $O$.

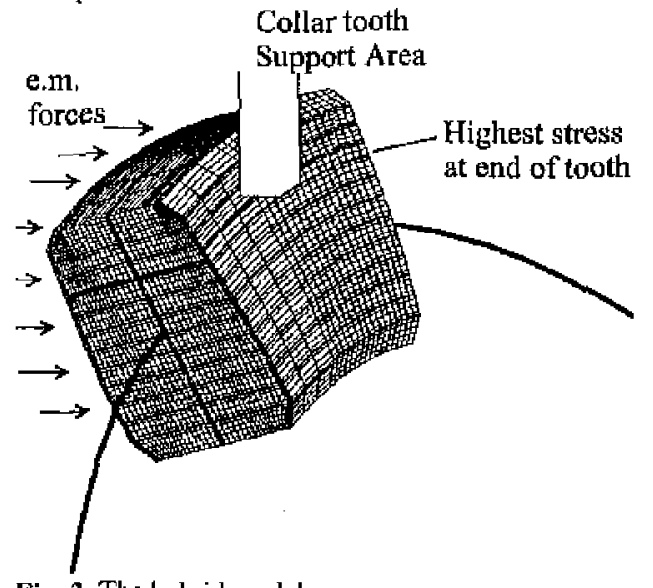

Fig. 2. The hybrid model.

\section{Tests and ANalysis ON THE COIL Insulation}

Optical examination and mechanical tests were carried out to investigate the mechanical properties and condition of the coil insulation, in particular the interturn insulation. Its constituents are glass fibres vacuum impregnated with epoxy resiu. The resin composition is Araldite CY205 Hardener HY906 - Flexibilizer DY040. Samples were cut from stices of the first faulty coil at various positions, so as to inerease the statistics of the results.

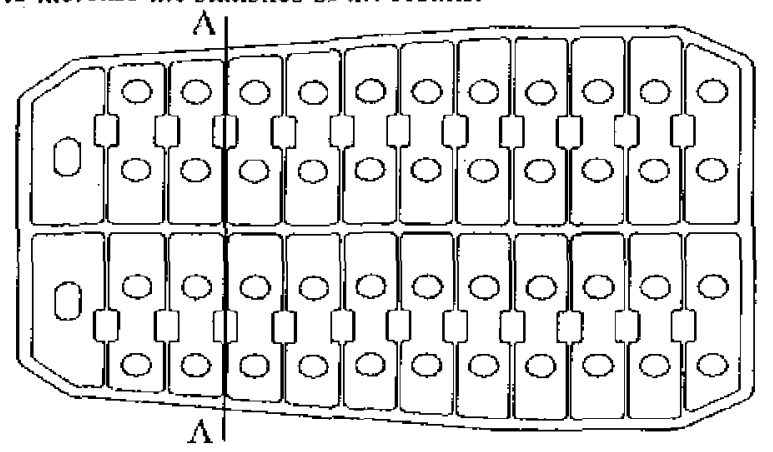

Fig. 3. A cross section of the TF coil.

\section{A. Measurement of $G$ with Losipescu Method}

The shear stress in the insulation is strongly affected by $\mathrm{G}$, therefore it is of the utmost interest to measure this parameter. Since cylindrical samples for standard measurement of shear properties could not be machined out of the available material of the eoil, the Iosipescu method for the measurement of $G$ on rectangular samples was implemented [3]. This is a standard method designed to produce shear property data of composite materials. A rectangular sample with symmetrical centrally located Vnotches is loaded in a mechanical tesling machine by a special fixture designed to produce purc shear stress. The notches improve uniformity of the shear strain distribution along the loading direction. Any twisting of the sample is corrected through the readings from strajn gauges on both sides of the sample. 18 samples wero tested according to the standard and the $\tau-\gamma$ curve recorded up to failure. 'The effect of temperature was also investigated. For our measured ultimate shear strain capability the $G$ value is derived from the chord in the shear strain range $1000 \div 6000$ je.

$$
G=\frac{\Delta \tau}{\Delta \gamma}
$$

Preload test up to maximum $5 \mathrm{MPa}$ at the 3 diffecent temperatures $\mathrm{T}=20^{\circ} \mathrm{C}, \mathrm{T}=70^{\circ} \mathrm{C}$ and $\mathrm{T}=90^{\circ} \mathrm{C}$ and failute test at the chosen temperature were performed on each simple. The averaged $G$ drastically decreases with temperature from $3700 \mathrm{MPa}$ at room temperature down to about $2600 \mathrm{MPa}$ at $70^{\circ} \mathrm{C}$ and $1400 \mathrm{MPa}$ at $90^{\circ} \mathrm{C}$, Fig. 4. The preload test gives the possibility to compare the $G$ value of the same sample at the 3 different temperatures. Results from these tests give a constant $G$ at low temperature, while $G$ drastically decreases with the shear load increase at higb tempetature.

Preliminary calibration was catricd out on a sample with well known $G$, which confirm reliability of the method within few petcent.

Moreover finite elements analysis was carried out to check the stress field and sensitivity of $\mathrm{G}$ with the glass-resin content. A maximum $15 \%$ uncertainty was found botween the computed and the measured $\mathrm{G}$ for the same glass-resin composition. This gave contidence for computing the $G$ valuc of the key instlation, knowing its composition.

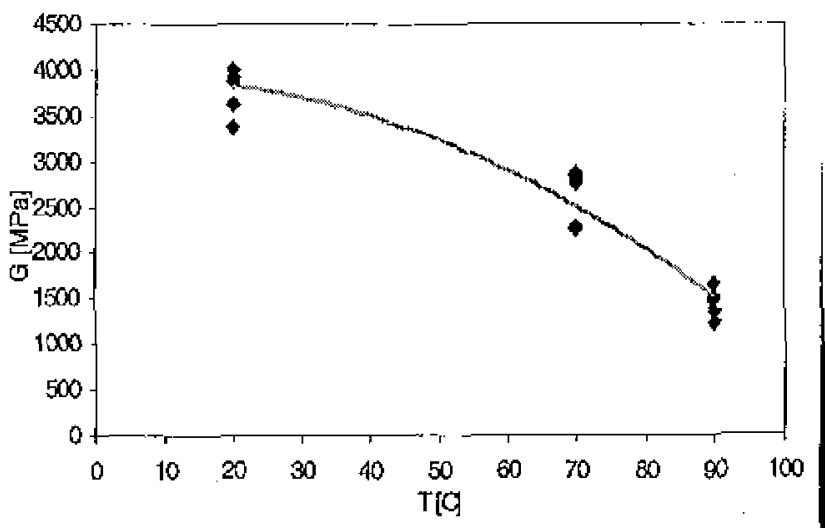

Fig. 4. Variability of $\mathrm{G}$ with temperature (Iosipeseu samples). 


\section{B. Shear Strength with losipeseu Method}

The obtained data allow also for investigation of the sheat strength capability of the insulation and its sensilivity with temperature, Fig. 5. Results show bigher average with lower scatter compared with previous tests on conventional small rectangular samples, Fig. 6, and on double shear samples [1], thus improving confidetice of the result. Fig. 7 shows the geometry of the different samples.

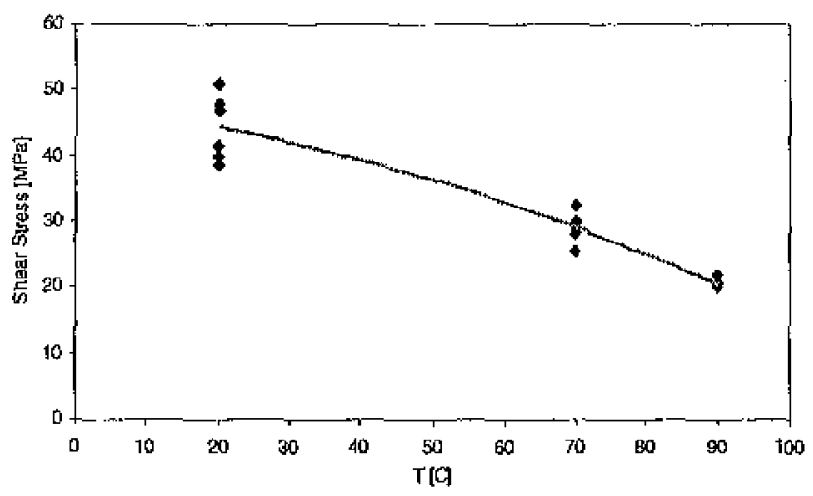

Fig. S. Shear strength versus temperaure (Iosipescu samples).

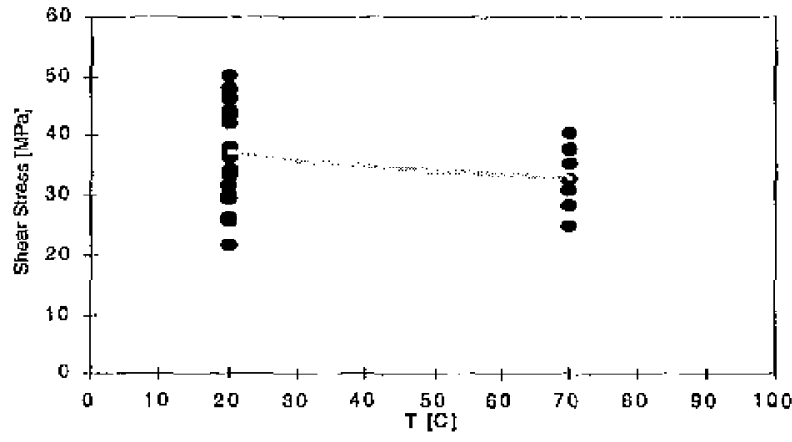

Fig. 6. Shear strength versus temperature (small samples),

The contact failure is defined as the percentnge lack of rosin over the total aten. The void content is a volumeitic measurement of voids, therofore it is a quantitative measurement of the percentage lack of resin in the sample volume. The quatitative information on the shape, concentration and topology of the voids is given by the contaet failure. The contact failure is then the property which may explain the sprend of shear strength in the moasurcments. Fig. 8 shows the corrclation between contact failure and shear strength obtained by microseopic analysis in the failed area of the broken sample at room temperature for both Iosipeseu and small samples. From tho failuro mode atralysis 2 main failure mechanisms were observed, at the pre-preg layer in the center of the insulation and at the copper/insulation interface. The number of samples which break at the pre-preg layer is higher, thus confirming that the weakest point of the coil is related to the technological choices of the matufacturing cycle more than on the quality of the impregnation.
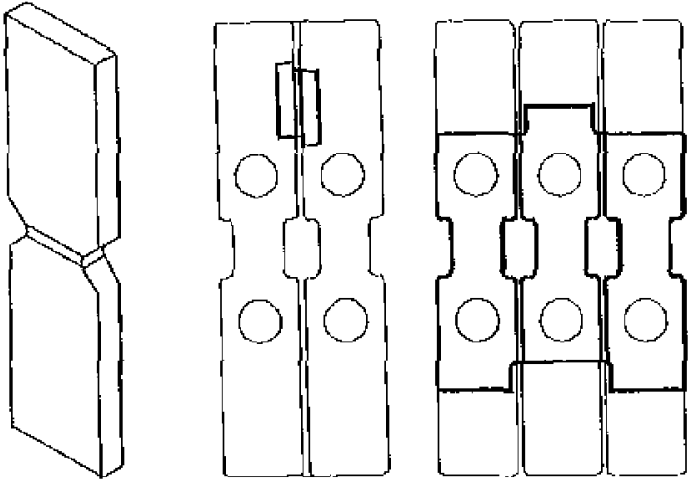

Fig. 7. Iosipescu, small and double shear samples.

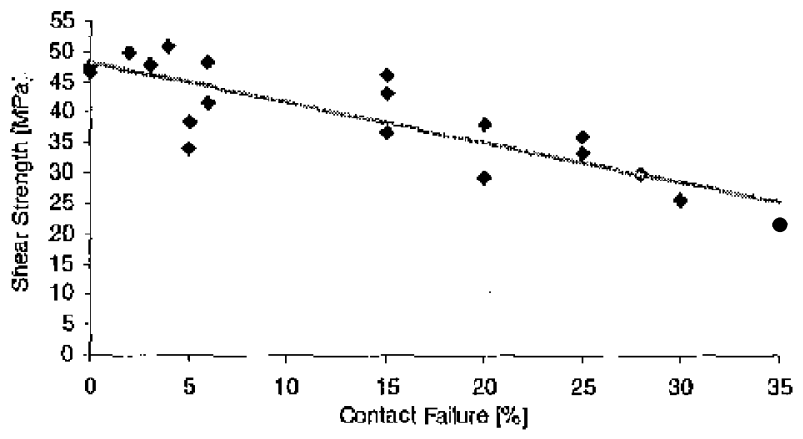

Fig. 8. Shear strength against contact failure at room temperature (Iosipescu and small samples).

\section{Fatigue Tests}

Fatigue tests were performed on conventional small samples with the cumulative damage technique. This allows for the determination of the S-N curve using less samples than the standard fatigue test method. The same sample is cycled for a chosen number of cycles, i.e. 20000 as it demonstrates double the required life, with a frequency $F=0.83 \mathrm{H}_{7, \text { at }}$ at different stress levols wilh constant stress steps up to failure. The effect of the previous cycling is allowed for by cumulative damage calculations. 7 samples were tested at $\mathrm{T}=20^{\circ} \mathrm{C}$ and 6 at $\mathrm{T}=90^{\circ} \mathrm{C}$, Fig. 9 .

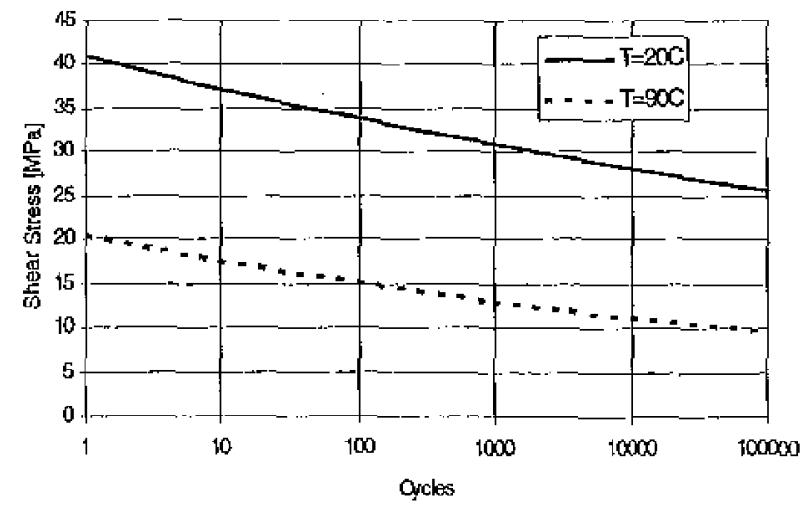

Fig. 9. Fatigue curves at temperature 20 and $90^{\circ} \mathrm{C}$ (small samples). 
Other fatigue tests were performed on double shear salnples at the different temperatures $\mathrm{l}^{\prime}=20^{\circ} \mathrm{C}, \mathrm{T}=70^{\circ} \mathrm{C}$ and $\mathrm{T}=90^{\circ} \mathrm{C}$, Fig. 10. The curves at roon temperature are very similar, while they are different at high temperature. In particular the double shear satmples give better result at high temperature: this is mainly due to the test fregutency which is a factor 10 higher. Preliminary croep tests show a clcar creep effect already at temperatare $\mathrm{T}=70^{\circ} \mathrm{C}$, which implics that the total time at maximum load affects the fatigue behawior at temperature. Fig. 11 shows the fatigue curve at room temperature obtained with Iosipescu samples and the standard fatigte method. The 3 curves at room temperature are very similar, thus increasing confidence on the result.

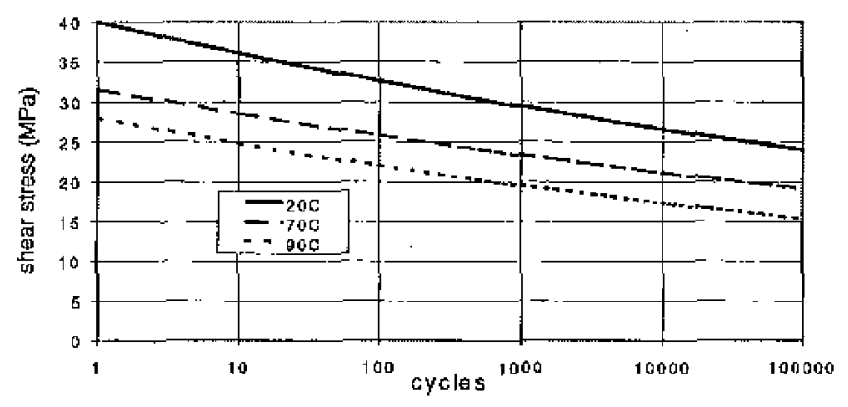

Fig. 10. Fatiguc curves at $20,70,90^{\circ} \mathrm{C}$ (double slear samples).

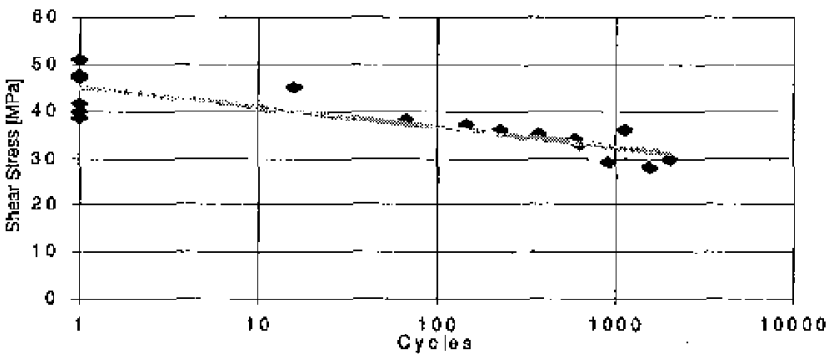

Fig. 11. Fatigue curve at $20^{\circ} \mathrm{C}$ (Iosipcscu samples).

\section{Micrographic Examination}

The tests could not be done on samples cut from the curved . region at the collar position due to the built-in residual stress. Therefore to investigate the status of the insulation in this position, micrographic analysts and comparison of the result werc performed at correspondent positions of the coil section in the straight and curved regions. 7 plis 7 interlurn samples were analyzed taking into account also the sample position of the previous tests, in order to study possible correlation between the different parameters. Void content [4] and glass-resin content [5] was performed through calcination of a sample. Moreover micrographic analysis of the 2 sections adjacent to the sample was carried out to study the morphology of the defects. The average void content is $0.66 \%$, in particular $0.64 \%$ in the straight region and $0.68 \%$ in the curved one. This confirms the good quality of the impreguation, since the limit reported in the standard is $1 \%$. These voits are mainly due to the resin shrinkage, during the polymerization process and their main shape resembles a flattened sphere, which gives a lower overall weakening. The average glass content is $63.6 \%$ and the resin content $35.7 \%$ and are not significantly diflerent in the 2 analyzed regions. The lowest measured $\mathrm{G}$ does not correspond to a sample with the lowest glass and void content as expected, which implics that the glass content and void content have no correlation with the $\mathrm{G}$ values. This confirms that within the observal variability of the measurements, the mechanical properties of the insulation are not affected from tegton to region. The voids observed by micros show the same pallern and comparable concentration in the 2 regions and are mainly die to little ais bubbles trapped during the manufactujing cycle in the 2 layers of pre-preg positioned in the middle of the inter-turn insulation. The shape of these voids suggests that they kept their shape and dimension since then. As already mentioned no corrolation was found betweon void content and shear strength, while a correlation exists between contact failurc and shear strength, Fig. 8.

\section{E. Second Order Glass Transition Temperature (GTT)}

GTT moasurement was performed on different samples by both the Differential Scanning Calorimetry and the Differential Thermal Analysis [6]. The averaged GTT is $109^{\circ} \mathrm{C}$, ranging from $105^{\circ} \mathrm{C}$ to $115^{\circ} \mathrm{C}$. This level of temperatures explains the drastic fall of shear resistance observed in both static and fatigue tests performed at $\mathrm{T}=90^{\circ} \mathrm{C}$. From correlation analysis on correspondent samples, GTT increases with $G$ at the same glass content.

\section{CONCLUSIONS}

The results achieved confirm the good status of the coil insulation. It must be emphasized that the samples are cut from a real coil which has been operational in the JET machine for years, while normally new laboratory made samples are used for the tests. This increases our confidence on the results. The Iosipescu method for the $G$ moasurement was extended to determine also the shear strength and the fatigue behavior and gives results that are remarkably good. The results obtained allow for definition of allowables and fatigue limits. Fatigue tests with different samples give approximately the same fatigue curve at room temperature, which is the basis for the faligue assessment of the I'F coils. The result from this work is the basis for the reliability assessment of the JET machine and acceptance of its upgrade to 4 tesla operation for improved performance.

Acknowledgments

Thanks are due to $M$ Gasparotto, $S$ Tosti and L Verdinj for their contribution to this work.

\section{REFERENCES}

[i] J Last et al, 'Analysis and Tests in support of Upgrading the JET Toroidal Field to 4 Tesla', MT-15, 1997.

[2) P Miele of al. 'Mechanical Assessment of the JET TF Coils for 4T Upgrade: the New 3D Hybricl Model', SOFT-20, 1998.

[3] ASTM D 5379/D 5379M - 93 .

[4] ASTM D 2734-9].

[5] ASTM D 2584-85

[6] ASTM E 1356-9]. 